\title{
Admission hypoxia-inducible factor $1 a$ levels and in-hospital mortality in patients with acute decompensated heart failure
}

\author{
Gang $\mathrm{Li}^{i^{*}}$, Wei-hua $\mathrm{Lu}^{1+}$, Xiao-wei $\mathrm{Wu}^{2}$, Jian Cheng ${ }^{1}$, Rong Ai ${ }^{3}$, Zi-hua Zhou ${ }^{4}$ and Zhong-zhi Tang ${ }^{1}$
}

\begin{abstract}
Background: Hypoxia-inducible factor 1 (HIF-1) is a critical regulator for cellular oxygen balance. Myocardial hypoxia can induce the increased expression of HIF-1a. Our goals were to evaluate the value of HIF-1a in predicting death of patients with acute decompensated heart failure (ADHF) and describe the in vivo relationship between serum HIF-1a and N-terminal-pro-brain natriuretic peptide (NT-proBNP) levels.

Method: We included 296 patients who were consecutively admitted to the emergency department for ADHF. The primary end point was in-hospital death. The patients were categorized as HFrEF (patients with reduced systolic function) and HFpEF (patients with preserved systolic function) groups.

Results: In our patients, the median admission HIF-1a level was $2.95 \pm 0.85 \mathrm{ng} / \mathrm{ml}$. The HIF-1a level was elevated significantly in HFrEF patients and deceased patients compared with HFpEF patients and patients who survived. The HIF-1 a level was positively correlated with NT-proBNP and cardiac troponin T levels, and negatively correlated with left ventricular ejection fraction and systolic blood pressure. Kaplan-Meier curves revealed a significant increase in in-hospital mortality in ADHF patients with higher HIF-1a levels. Multivariable Cox regression analysis showed that HIF-1 a levels were not correlated with the short-term prognosis of ADHF patients.
\end{abstract}

Conclusions: This is the first study to evaluate the circulating levels of HIF-1a in ADHF patients. Serum HIF-1a levels may reflect a serious state in patients with ADHF. Due to the limitations of the study, serum HIF-1a levels were not correlated with the in-hospital mortality based on regression analysis. Further studies are needed to demonstrate the diagnostic and/or prognostic role of HIF-1a as a risk biomarker in patients with ADHF.

Keywords: Hypoxia-inducible factor 1a, Acute decompensated heart failure, N-terminal-pro-brain natriuretic peptide, In-hospital mortality

\section{Background}

Heart failure is a common cardiovascular disease. Cardiac dysfunction may induce inadequate tissue perfusion, which leads to hypoxic ischemia of many organs. When myocardial cells are hypoxic, glucose serves as the substrate for glycolysis and fatty acids are converted to lipids [1, 2]; however, hypoxic myocardial cells cannot produce sufficient adenosine triphosphate to maintain cardiac function. The loss in efficacy of cardiac function is characterized by a decrease in the ejection fraction,

\footnotetext{
*Correspondence: marty007@163.com

${ }^{\dagger}$ Equal contributors

'Emergency Department, Wuhan General Hospital of Guangzhou Military

Command, Wuhan 430074, China

Full list of author information is available at the end of the article
}

an increase in left ventricular end-diastolic diameter (LVEDD), and the emergence of clinical symptoms and signs of heart failure [3, 4]. Intracellular tissue adaptation to hypoxia is mediated by hypoxia-inducible factor 1 (HIF-1), which is a key mediator in the transformation from oxidation to glycolysis [5]. In addition, the conversion from fatty acids to lipids is also mediated by HIF-1 [6].

HIF-1 is a transcription factor and a critical regulator for cellular oxygen balance. HIF-1 is a heterodimer comprised of two sub-units ( $\alpha$ and $\beta$ ). HIF-1 $\alpha$ controls oxygen transfer by regulating angiogenesis and vascular remodeling [7]. Moreover, the utility of oxygen is also controlled by HIF-1 via regulation of glucose metabolism and redox 
equilibrium [8]. A previous study showed that the expression of HIF- $1 \alpha$ is increased significantly in patients with myocardial hypoxia [9]. As a transcription factor, HIF-1 $\alpha$ mediates important physiologic responses during hypoxia by regulating downstream target genes to make the body produce compensatory adaptations to myocardial hypoxia. Animal models have shown that HIF-1 $\alpha$ has a critical protective effect on the pathophysiology underlying ischemic heart disease $[7,10,11]$ and pressure overload heart failure [12].

B-type natriuretic peptide (BNP) is primarily synthesized in ventricular cells $[13,14]$ and plays an important role in maintaining fluid balance and adjusting blood pressure [15]. Especially in patients with acute decompensated heart failure (ADHF), an elevated admission BNP level is a significant predictor of in-hospital mortality [16-18]. The synthesis of BNP is directly caused by hypoxia mediated through a HIF- $1 \alpha$-independent mechanism not influenced by hemodynamics or stimulation of neurohormones based on an in vitro ventricular myocyte model system [19]. BNP appears to be part of the protective program directed by HIF- $1 \alpha$ in response to oxygen deprivation [20]. Cumulative experimental data have clearly shown that hypoxia is an independent factor regulating the natriuretic peptide system [21]. Additionally, hypoxia-response elements have been characterized from the promoter sequences of the ANP and BNP genes $[20,22,23]$; however, as an upstream regulation factor of BNP, the role of HIF- $1 \alpha$ in ADHF patients has not been studied. In the current study we investigated whether or not the admission HIF- $1 \alpha$ level predicted in-hospital mortality of ADHF patients and clarified the in vivo relationship between $\mathrm{N}$-terminal-pro-brain natriuretic peptide (NT-proBNP).

\section{Methods \\ Patients}

Two hundred ninety-six patients with typical heart failure symptoms and signs were enrolled in the investigation conducted in conjunction with the Emergency Department. The criteria recommended by the most recent guidelines of the European Cardiology Society (ESC) and the American College of Cardiology Foundation/ American Heart Association (ACCF/AHA) were adopted for the classification of patients enrolled in this study [24, 25]. Specifically, the inclusion criteria were as follows: patients had presented within the previous $24 \mathrm{~h}$ with ADHF; diagnosed on the basis of the presence of at least one symptom (dyspnea, orthopnea, or edema) and one sign (rales, peripheral edema, ascites, or pulmonary vascular congestion on chest radiography) of heart failure; NYHA functional class III or IV, with an acute exacerbation of symptoms of at least 1 class; evidence of systolic and/or diastolic dysfunction by echocardiography; > 18 years of age; and NT-proBNP $\geq 1800 \mathrm{pg} / \mathrm{ml}$. The NT-proBNP cut-off value of $1800 \mathrm{pg} / \mathrm{ml}$ was selected to increase specificity. The exclusion criteria were as follows: patients with tumors, unstable angina, or recent acute myocardial infarction, current or past dialysis; and patients in shock or without the company of a lineal relative and could not sign the informed consent. This study complied with the Helsinki Treaty. All participants signed the written informed consent form. Our study was approved by the Institutional Ethics Committee of Wuhan General Hospital of Guangzhou Military Command.

\section{Biochemical measurements}

After patients signed the informed consent, blood samples were obtained immediately. The blood samples were centrifuged at $3000 \mathrm{rpm}$ at $4{ }^{\circ} \mathrm{C}$ for $15 \mathrm{~min}$. The supernatants were decanted and frozen at $-80{ }^{\circ} \mathrm{C}$ until assayed. Serum creatinine, uric acid (UC), blood urea nitrogen (BUN), and high-sensitive $\mathrm{C}$-reactive protein (hs-CRP) levels were determined in the hospital laboratory using standard methods. Enzyme-linked immunosorbent assay (ELISA) kits were used to measure serum levels of HIF- $1 \alpha$ (Abnova, Taiwan). Intra- and inter-assay coefficients of variation for HIF- $1 \alpha$ were $4.2 \%$ and $7.6 \%$, respectively. The lower limit of detection (LOD) was $0.041 \mathrm{ng} / \mathrm{ml}$ and the reference value interval was $0.078-5.0 \mathrm{ng} / \mathrm{ml}$. The plasma levels of NT-proBNP were determined using the Elecsys proBNP assay (Roche Diagnostics, Basel, Switzerland) [26]. The intra-assay coefficients of variation are $2.4 \%$ and $1.8 \%$ at 355 and $4962 \mathrm{pg} / \mathrm{ml}$, respectively, and the respective inter-assay coefficients of variation were $2.9 \%$ and $2.3 \%$, respectively. We measured $\mathrm{TnT}$ levels using a commercial one-step enzyme immunoassay (EIA) based on electrochemiluminescence technology (fourth-generation TnT, Elecsys 2010; Roche Diagnostics). The lower limit of detection of this assay was $10 \mathrm{ng} / \mathrm{L}$, with a recommended diagnostic threshold of $30 \mathrm{ng} / \mathrm{L}$. At this concentration, TnT concentrations can be measured with a coefficient of variation $(\mathrm{CV})$ of $<10 \%$ [27].

\section{Echocardiography}

Patients were simultaneously evaluated with twodimensional echocardiogram using standard views and protocols [28]. Pulsed-wave Doppler echocardiography was performed by an experienced cardiologist with a Hewlett Packard Sonos 1000 ultrasound system and a 2.5$\mathrm{MHz}$ transducer (Palo Alto, California, USA). The main parameter which was evaluated was the left ventricular ejection fraction (LVEF). The patients were categorized as $\mathrm{HF} r \mathrm{EF}$ (patients with reduced systolic function [LVEF $\leq$ $40 \%]$ ) and $\operatorname{HF} p \mathrm{EF}$ (patients with preserved systolic function [LVEF $>40 \%]$ groups [25]. Doppler echocardiographic indices (e', E/e' ratio, left atrial volume index and LV mass index) to measure diastolic dysfunction were 
evaluated as recommended by ESC and ACCF/AHA guidelines $[24,25]$. The diagnosis of HFpEF in our patients requires 3 conditions to be satisfied: typical symptoms and signs of HF, normal LVEF and LV not dilated, left ventricular diastolic dysfunction.

\section{Statistical analysis}

SPSS version 18.0 (SPSS Inc, Chicago, Illinois) statistical software was used for statistical analysis. Continuous variables in a normal distribution were compared using the Student's $t$-test and ANOVA. Categorical variables

Table 1 Clinical and laboratory data for 296 patients with acute decompensated heart failure

\begin{tabular}{|c|c|c|c|}
\hline \multirow[t]{2}{*}{ Variable } & \multirow{2}{*}{$\begin{array}{l}\text { HFpEF } \\
(n=108)\end{array}$} & \multirow{2}{*}{$\begin{array}{l}\text { HFrEF } \\
(n=188)\end{array}$} & \multirow[t]{2}{*}{$P$ Value } \\
\hline & & & \\
\hline Age (years) & $74.0 \pm 10.2$ & $73.3 \pm 10.5$ & 0.599 \\
\hline Male $n,(\%)$ & $77(71.3 \%)$ & $118(62.8 \%)$ & 0.161 \\
\hline \multicolumn{4}{|l|}{ History } \\
\hline Coronary artery disease $n,(\%)$ & $58(53.7 \%)$ & $96(51.25 \%)$ & 0.717 \\
\hline Hypertension $n,(\%)$ & $79(73.1 \%)$ & $132(70.2 \%)$ & 0.689 \\
\hline Previous heart failure $n,(\%)$ & $62(57.4 \%)$ & $90(47.9 \%)$ & 0.118 \\
\hline Diabetes mellitus $n,(\%)$ & $49(45.4 \%)$ & $100(53.2 \%)$ & 0.227 \\
\hline COPD/asthma n, (\%) & $27(25 \%)$ & $40(21.3 \%)$ & 0.474 \\
\hline Atrial fibrillation $n,(\%)$ & $35(32.4 \%)$ & $55(29.3 \%)$ & 0.601 \\
\hline Chronic renal insufficiency $n,(\%)$ & $22(20.4 \%)$ & $44(23.4 \%)$ & 0.883 \\
\hline Cardiac valvular disease $n,(\%)$ & $30(27.8 \%)$ & $39(20.7 \%)$ & 0.199 \\
\hline \multicolumn{4}{|c|}{ Intravenous medications during hospitalization } \\
\hline Diuretics $n,(\%)$ & $97(89.8 \%)$ & $172(91.5 \%)$ & 0.677 \\
\hline Cedilanid $n,(\%)$ & $38(35.2 \%)$ & $89(47.3 \%)$ & 0.051 \\
\hline Nitroglycerin $n,(\%)$ & $10(9.3 \%)$ & $59(31.4 \%)$ & 0.522 \\
\hline Nitroprusside $n,(\%)$ & $10(9.3 \%)$ & $23(12.2 \%)$ & 0.565 \\
\hline \multicolumn{4}{|c|}{ Oral medications during hospitalization } \\
\hline ACE inhibitors $n,(\%)$ & $61(56.5 \%)$ & $121(64.4 \%)$ & 0.215 \\
\hline ARB $n,(\%)$ & $23(21.3 \%)$ & $30(16.0 \%)$ & 0.272 \\
\hline Beta-blocker $n,(\%)$ & $73(67.6 \%)$ & $141(75 \%)$ & 0.180 \\
\hline Calcium channel blocker $n$, (\%) & $19(17.6 \%)$ & $42(22.3 \%)$ & 0.372 \\
\hline Digoxin $n,(\%)$ & $47(43.5 \%)$ & $110(58.5 \%)$ & 0.016 \\
\hline Diuretics $n,(\%)$ & $68(63.0 \%)$ & $38(20.2 \%)$ & 0.462 \\
\hline Warfarin $n,(\%)$ & $25(23.1 \%)$ & $50(26.6 \%)$ & 0.579 \\
\hline Death $n,(\%)$ & $6(5.6 \%)$ & $15(8.0 \%)$ & 0.490 \\
\hline Admission SBP (mmHg) & $155.0 \pm 28.5$ & $144.6 \pm 29.7$ & 0.003 \\
\hline Admission DBP (mmHg) & $80.4 \pm 15.2$ & $78.3 \pm 13.8$ & 0.556 \\
\hline BMI $\left(\mathrm{kg} / \mathrm{m}^{2}\right)$ & $23.5 \pm 2.8$ & $23.1 \pm 2.6$ & 0.354 \\
\hline HR (bpm) & $90.0 \pm 17.2$ & $89.4 \pm 19.0$ & 0.677 \\
\hline HIF-1a(ng/ml) & $2.70 \pm 0.78$ & $3.37 \pm 0.79$ & 0.001 \\
\hline NT-proBNP(ng/L) & $6826.7 \pm 7049.4$ & $9297.7 \pm 8359.8$ & 0.007 \\
\hline $\operatorname{TnT}(n g / L)$ & $85.5 \pm 163.5$ & $143.4 \pm 241.1$ & 0.015 \\
\hline hs-CRP (mg/l) & $8.5 \pm 5.7$ & $9.2 \pm 7.1$ & 0.059 \\
\hline D-dimer (ng/ml) & $294.4 \pm 486.8$ & $242.7 \pm 312.3$ & 0.302 \\
\hline Creatinine (ummol/l) & $98.0 \pm 45.4$ & $100.8 \pm 56.6$ & 0.744 \\
\hline UA (ummol/l) & $407.3 \pm 137.4$ & $389.2 \pm 147.4$ & 0.644 \\
\hline $\mathrm{BUN}(\mathrm{mmol} / \mathrm{L})$ & $10.2 \pm 4.5$ & $9.8 \pm 5.1$ & 0.521 \\
\hline
\end{tabular}

Abbreviations: SBP systolic blood pressure, DBP diastolic blood pressure, BNP B-type natriuretic peptide, $h s$-CRP high sensitivity C-reactive protein, CTNI cardiac troponin I, HR heart rate, TC total cholesterol, HDL highdensity lipoprotein cholesterol, LDL low-density lipoprotein cholesterol, UA uric acid 
were analyzed using the chi-squared test. Pearson correlation analysis was used to assess the correlation between HIF- $1 \alpha$ level and other cardiovascular disease risk factors. In order to clear whether the HIF-1 $\alpha$ levels can predict the in-hospital mortality of ADHF patients, multivariate logistic regression models was used for the analysis. In the logistic regression models, we performed log-transformation of NT-proBNP and TnT. Survival curves were estimated according to the Kaplan-Meier method and compared by the log-rank test. Additionally, receiver operating characteristic analysis was performed to determine the cut-off value for HIF- $1 \alpha$ in predicting type of ADHF with high sensitivity and specificity. $P$ value $<0.05$ was considered statistical significant.

\section{Results}

A total of 296 ADHF patients were enrolled between January 2011 and March 2014 at 4 clinical sites (Wuhan, China). Meanwhile, we also enrolled 52 healthy volunteers (mean age: $43.8 \pm 18.5$; male: $67.3 \%$ ) as control group. Of these ADHF patients, 21(7.1 \%) died in hospital. In Table 1, baseline characteristics of patients are described. Among them, 195(65.9\%) cases were male. The mean age was $73.5 \pm 10.4$ years old. There were 188 (63.5 \%) patients with HFrEF (median LVEF $35 \%$ ) and 108 (36.5 \%) patients with HFpEF (median LVEF $52 \%$ ).

In our ADHF patients, the mean HIF-1 $\alpha$ level was $2.95 \pm 0.85 \mathrm{ng} / \mathrm{ml}$ and significantly higher than healthy subjects $(1.31 \pm 0.47 \mathrm{ng} / \mathrm{ml}, p<0.001)$. However, serum HIF- $1 \alpha$ levels in the HFrEF patients were significantly higher than the HFpEF patients $(3.37 \pm 0.79$ vs $2.70 \pm$
$0.78 \mathrm{ng} / \mathrm{ml}, P=0.001$, Table 1 and Fig. 1$)$. During the study period, 21 patients died in hospital. In our findings, the HIF- $1 \alpha$ concentrations were significantly higher in death than in survival patients $(3.54 \pm 0.81$ vs $2.89 \pm$ $0.83 \mathrm{ng} / \mathrm{ml}, p<0.001$, Fig. 2). HIF- $1 \alpha$ levels positively correlated with NT-proBNP $(r=0.337, P<0.001)$, TnT $(r=0.357, P<0.001)$, and negatively correlated with LVEF $(r=-0.332, \quad P<0.001)$ and $\operatorname{SBP}(r=-0.145, \quad P=$ $0.013)$ but did not correlate with age, gender, hs-CRP, creatinine and HR (Fig. 3).

In the present study the in-hospital mortality was $7.9 \%$ (21 cases). The median hospital stay was $10.5 \pm$ 8.9 days. Univariate Cox regression model results showed that the serum HIF-1 $\alpha$ level predicts the risk of in-hospital mortality for ADHF patients (HR, 1.996; $95 \%$ CI, 1.252-3.182, $P=0.004$ [Table 2]); however, the final multivariate Cox regression model was performed using a stepwise method starting with variables that in univariate analysis were not associated with HIF-1 $\alpha$ level and the risk of in-hospital mortality (Table 3). We dichotomized patients into two groups according to the HIF-1 $\alpha$ median level. We found that the in-hospital mortality in the above median group was higher than the below median group (16 deaths vs. five deaths; $10.8 \%$ vs. $3.4 \%, p=0.022$ ). The Kaplan-Meier curves stratified according to the mean HIF- $1 \alpha$ level are shown in Fig. 4. Log-rank testing revealed a significant increase in in-hospital mortality in the above median group as compared with the below median group $(p=0.043)$.

We performed receiver operating characteristic analysis to determine the cut-off value of HIF-1 $\alpha$, NTproBNP and TnT in evaluating the type of ADHF of all

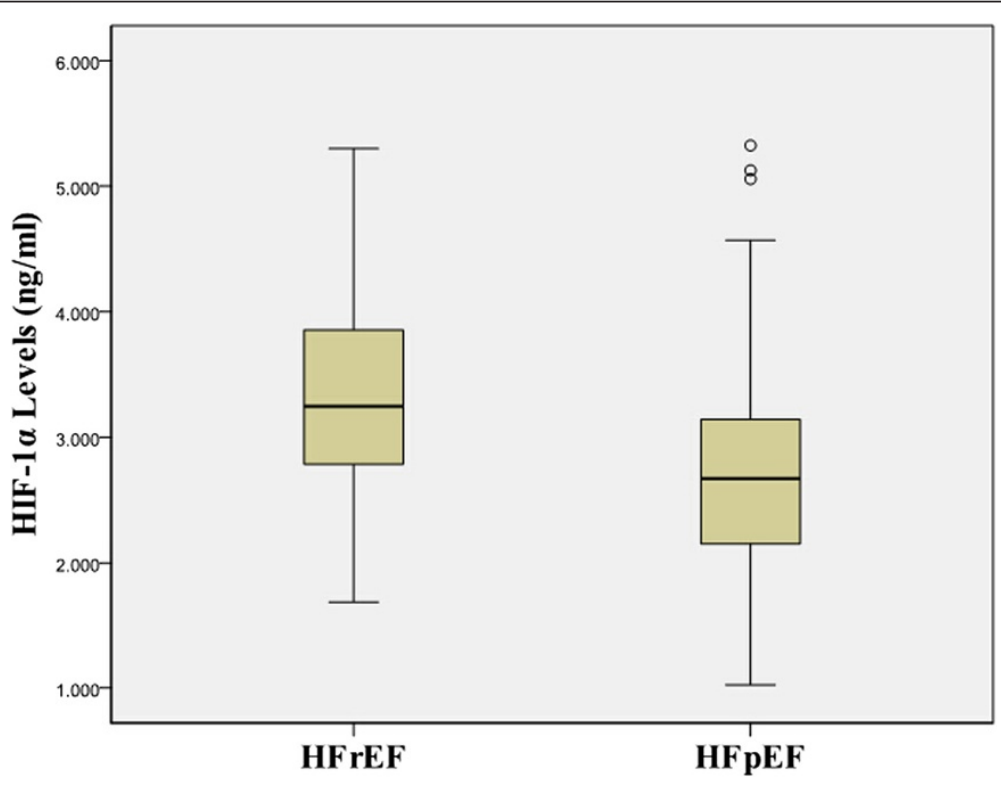

Fig. 1 Comparison of HIF-1a values between HFrEF and HFpEF groups 


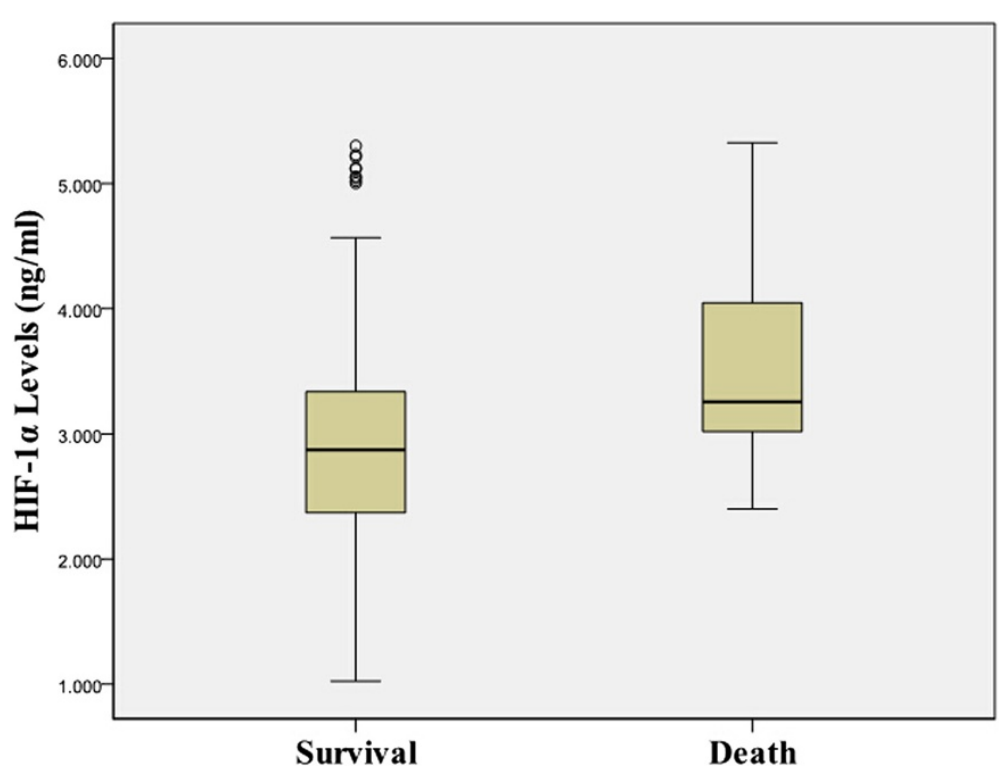

Fig. 2 Comparison of HIF-1a values between survival and death groups
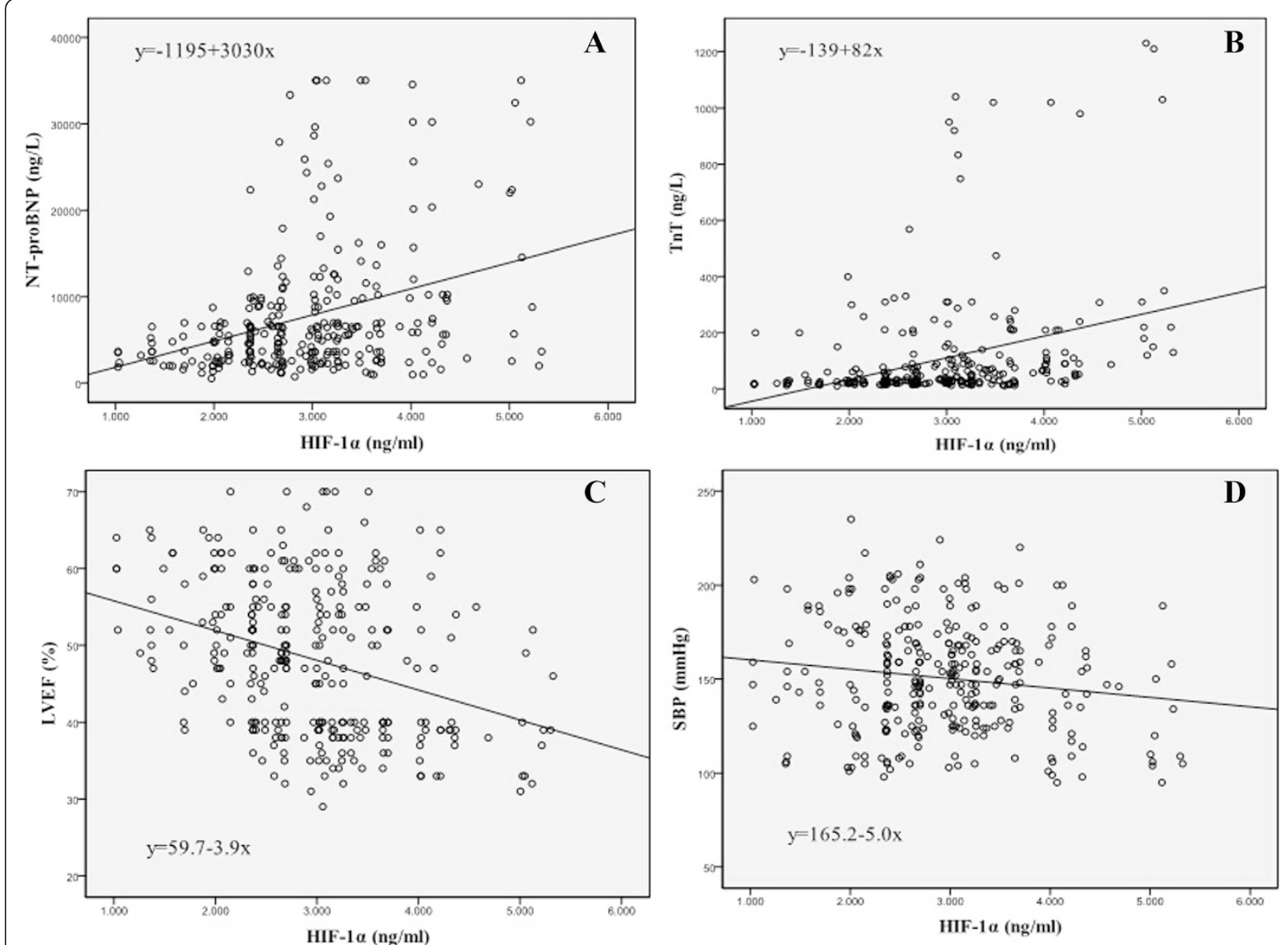

Fig. 3 Scatter plots for the correlations between HIF-1a and NT-proBNP, TnT, LVEF and SBP 
Table 2 Univariate Cox regression analysis for the identification of predictors of death

\begin{tabular}{|c|c|c|c|}
\hline & OR & $95 \% \mathrm{Cl}$ & $P$ Value \\
\hline Age(years) & 0.984 & $0.950-1.020$ & 0.388 \\
\hline Male & 0.992 & $0.407-2.415$ & 0.985 \\
\hline History of hypertension & 1.170 & $0.890-1.537$ & 0.261 \\
\hline History of DM & 1.252 & $0.481-3.258$ & 0.645 \\
\hline Previous heart failure & 1.425 & $1.119-4.449$ & 0.115 \\
\hline Abnormal ECG & 1.042 & $0.949-1.144$ & 0.391 \\
\hline Admission SBP & 1.003 & $0.989-1.017$ & 0.711 \\
\hline Admission DBP & 0.989 & $0.975-1.004$ & 0.141 \\
\hline HR & 0.980 & $0.957-1.003$ & 0.093 \\
\hline Nitroglycerin & 0.874 & $0.801-0.967$ & 0.754 \\
\hline Digoxin & 1.027 & $0.871-1.315$ & 0.249 \\
\hline Diuretics & 1.354 & $1.047-2.649$ & 0.321 \\
\hline ACE inhibitors & 1.144 & $0.977-2.042$ & 0.219 \\
\hline Beta-blocker & 0.907 & $0.865-1.141$ & 0.476 \\
\hline HIF-1a (ng/ml) & 1.996 & $1.252-3.182$ & 0.004 \\
\hline Type of ADHF & 3.946 & $1.613-9.652$ & 0.003 \\
\hline LVEF & 0.930 & $0.886-0.977$ & 0.004 \\
\hline Maximal aortic diameter & 1.037 & $0.997-1.079$ & 0.073 \\
\hline $\mathrm{TnT}(\mathrm{ng} / \mathrm{L})$ & 1.270 & $0.223-7.220$ & 0.788 \\
\hline hs-CRP (mg/l) & 0.983 & $0.921-1.049$ & 0.606 \\
\hline Creatinine (ummol/l) & 0.993 & $0.979-1.007$ & 0.342 \\
\hline BUN (mmol/L) & 1.085 & $1.019-1.155$ & 0.215 \\
\hline UA (ummol/l) & 0.996 & $0.987-1.006$ & 0.444 \\
\hline
\end{tabular}

patients. The best cut-off value with HIF- $1 \alpha$, NTproBNP and TnT were $2.998 \mathrm{ng} / \mathrm{ml}$ (95 \% CI: 2.3572.998; sensitivity: $71.30 \%$; specificity: $67.02 \%, P<$ 0.0001), $5573 \mathrm{ng} / \mathrm{L}$ (95 \% CI: 2547-6587; sensitivity: $62.04 \%$; specificity: $59.04 \%, P=0.0005)$ and $86 \mathrm{ng} / \mathrm{L}$ (95 \% CI: 47-180; sensitivity: $52.17 \%$; specificity: $74.73 \%, P<0.0001)$. The area under the curve were 0.730(95 \% CI: 0.676-0.780, $P<0.0001$ ), 0.617(95 \% CI: 0.559 to $0.672, P=0.0005)$ and $0.662(95 \% \mathrm{CI}: 0.605-$ $0.715, P<0.0001)$ for HIF-1 $\alpha$, NT-proBNP and TnT, respectively (Table 4 and Fig. 5).

Table 3 HIF-1a levels predict the risk of in-hospital mortality for Cox regression model

\begin{tabular}{llc}
\hline HIF-1a & HR $(95 \% \mathrm{Cl})$ & $P$ Value \\
\hline Unadjusted & $1.996(1.252-3.182)$ & 0.004 \\
Model 1 & $1.633(0.999-2.672)$ & 0.051 \\
Model 2 & $1.724(1.024-2.904)$ & 0.040 \\
Model 3 & $1.128(0.594-2.140)$ & 0.713 \\
\hline
\end{tabular}

Model 1 age, type of ADHF and sex, Model 2 Model $1+$ SBP, LVEF and HR, Model 3 Model 2+ creatinine, hs-CRP, NT-proBNP and TnT

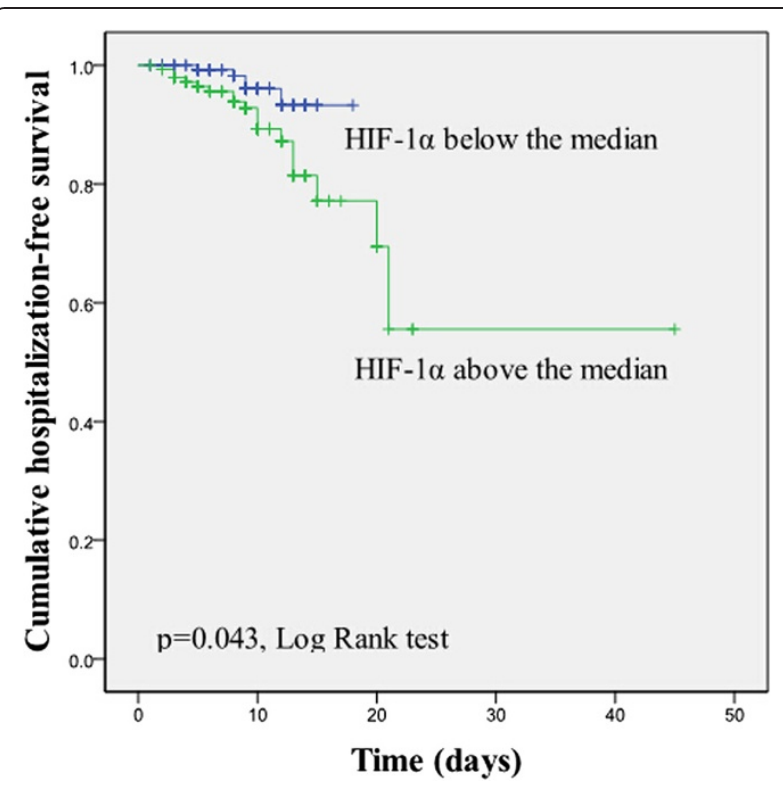

Fig. 4 Cumulative hospitalization-free survival according to serum HIF-1a level (median: $2.95 \pm 0.85 \mathrm{ng} / \mathrm{ml}$ )

\section{Discussion}

This is the first study to measure serum HIF-1 $\alpha$ levels in ADHF patients. We confirmed that HIF-1 $\alpha$ exists in the peripheral circulation of ADHF patients. The serum HIF- $1 \alpha$ level was associated with NT-proBNP, TnT, and LVEF. The level of HIF-1 $\alpha$ was elevated significantly in $\mathrm{HFrEF}$ and deceased patients compared with HFpEF and surviving patients. Kaplan-Meier curves revealed a significant increase in in-hospital mortality in ADHF patients with increased HIF- $1 \alpha$ levels. Based on a univariate Cox regression model, there was an association between HIF$1 \alpha$ and the risk of in-hospital mortality; however, multivariate Cox regression analysis showed that HIF-1 $\alpha$ cannot predict the short-term prognosis of ADHF patients.

Our study confirmed that the level of HIF-1 $\alpha$ was elevated significantly in HFrEF and deceased patients compared with HFpEF and surviving patients. This finding reflects more serious hypoxia in HFrEF and deceased patients. The significant reduction in cardiac systolic function, as well as inadequate blood perfusion of various organs, eventually led to severe hypoxia and a disordered internal environment. The previous study showed that myocardial hypoxia leads to increased expression of HIF- $1 \alpha[9,29]$. HIF- $1 \alpha$ induces the transcriptional activity of the downstream regulatory target gene, BNP [20]. Another in vitro study result showed that hypoxia increases the synthesis of AC16 cells and secretion of BNP through a HIF-1 $\alpha$-independent mechanism [19]. The current study was the first to confirm that there is a significant correlation between HIF- $1 \alpha$ and NT-proBNP in ADHF patients in vivo. Due to dysfunction of cardiac constriction, the levels of HIF-1 $\alpha$ and NT-proBNP were 
Table 4 Diagnostic value of HIF-1a, TnT and NT-proBNP for type of ADHF

\begin{tabular}{lllcccc}
\hline & AUC & Cut-off value & Sensitivity (\%) & Specificity (\%) & $95 \%$ Cl & $p$ Value \\
\hline HIF-1a & 0.730 & 3.62 & 35.2 & 90.0 & $0.676-0.780$ & $<0.0001$ \\
TnT & 0.662 & 0.12 & 42.6 & 82.5 & $0.598-0.725$ & $<0.0001$ \\
NT-proBNP & 0.502 & 19283 & 15.7 & 94.2 & $0.434-0.570$ & 0.955 \\
\hline
\end{tabular}

increased synchronously in HFrEF patients. Receiver operating characteristic (ROC) curve analysis indicated the value of HIF- $1 \alpha$ in predicting that the type of ADHF is superior to the NT-proBNP and TnT levels. These results provide evidence that HIF- $1 \alpha$ is tightly associated with ADHF.

Oxygen balance plays an important role in maintaining internal environment homeostasis. The oxygen concentration of cells is controlled precisely. This ingenious balance can be destroyed by heart disease, cancer, cerebrovascular disease, and chronic obstructive pulmonary disease [30]. As a transcription factor, HIF-1 is a key factor in maintaining oxygen balance in the human body $[7,11,30]$. In hypoxic conditions, HIF-1 is widely expressed in histocytes, mediates the hypoxic response, and induces gene expression related to the hypoxic response.

HIF- $1 \alpha$ is an intracellular protein. The current study first detected HIF- $1 \alpha$ in the peripheral circulation of ADHF patients. Under normal oxygen conditions, HIF$1 \alpha$ is extremely unstable with a half-life of $10 \mathrm{~min}$ [31]; however, under hypoxic conditions, intracellular hydrolysis of protein is prevented because proline and asparagine residues in HIF- $1 \alpha$ are not hydroxylated [32], which provides the possibility for intracellular to extracellular transfer. It has been reported that the level of

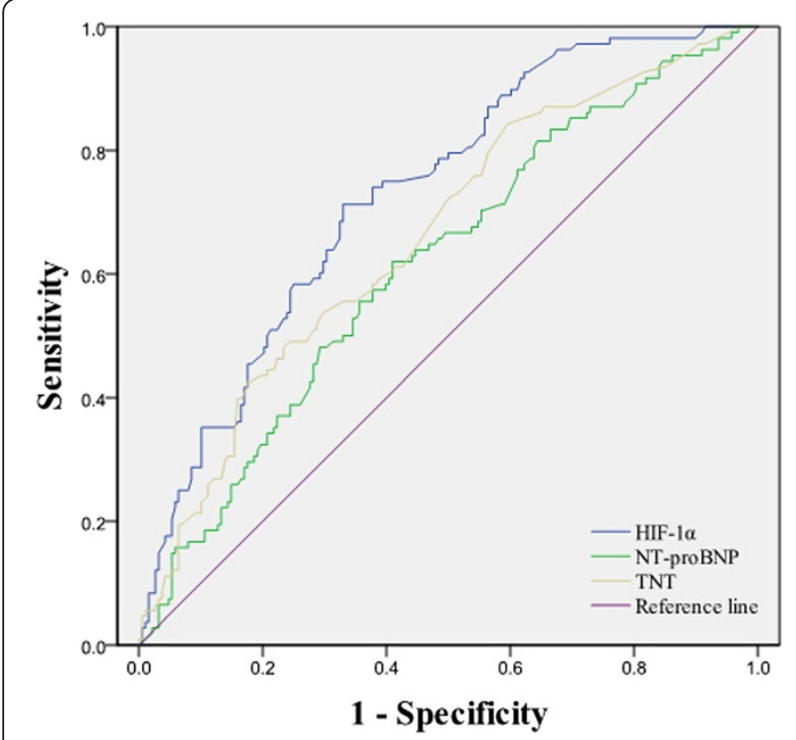

Fig. 5 Diagnostic value of HIF-1a, TnT and NT-proBNP for type of ADHF expression of HIF-1 can be maintain and is not decreased under sustained hypoxic conditions [33]. In ADHF patients, the level of expression of HIF- $1 \alpha$ increased greatly due to hypoxia and ischemia caused by hypoperfusion. In our previous study, the HIF- $1 \alpha$ level in patients with type II diabetes mellitus and coronary calcifications was measured [34]. We presumed that circulating HIF- $1 \alpha$ may be due to local cell apoptosis, which was induced by hypoxia. The potential underlying mechanism was likely high-mobility group box 1 (HMGB1), which reflects necrosis [35]. Under hypoxic conditions, HIF- $1 \alpha$ initiates expression of TNF- $\alpha$ in cardiomyocytes [36]. We assumed that the increase in the circulating HIF-1 $\alpha$ level reflects the severity of myocardial damage. Our findings indicate that there is a positive correlation between HIF- $1 \alpha$ and TnT.

HIF- $1 \alpha$ as a conditional knockout in myocardial cells will influence the maintenance of vascular endothelial growth factor (VEGF) expression [37] and angiogenesis [38]. It is essential for angiogenesis to increase oxidation transfer to compensate for hypertrophy. HIF-1 $\alpha$ deficiency will accelerate the onset of heart failure in TAC after 3 weeks [12]. In pressure overload-induced heart failure, HIF-1 $\alpha$ can protect heart failure [7]. The effect of HIF-1 has a complex pathophysiologic mechanism. During the development of cardiac hypertrophy, HIF-1 may have a protective effect and angiogenesis-promoting effect [39]; however, HIF-1 also has a pathogenic effect in terminal heart failure. As mediated by metabolism, heart failure is activated [7]. It has been reported that the cardiac function of HIF-1 $\alpha+/-$ is damaged [40] or improved [6] relative to wild-type mice. These controversial results may reflect the complexity of the adaptive response mediated by HIF-1.

In our study population the univariate Cox regression model and Kaplan-Meier curve results showed that HIF- $1 \alpha$ is a biomarker for predicting the risk of inhospital mortality in ADHF patients; however, the final multivariate Cox regression model indicated that the HIF- $1 \alpha$ level cannot predict the risk independently. Several hypotheses may explain this result. First, although HIF- $1 \alpha$ can sustain the level of expression under hypoxic conditions, HIF- $1 \alpha$, as an intracellular protein in the peripheral circulation, may be not stable. Second, previous studies have shown that digitalis can inhibit the synthesis of HIF-1 $\alpha$ [41]. In our patients, the administration of digitalis before admission and during hospitalization 
may affect the prognostic role of HIF- $1 \alpha$. Finally, oxygen inhalation during treatment in the hospital affects the expression of HIF-1 $\alpha$. With the improvement in the state of hypoxia, HIF-1 $\alpha$ levels may decline rapidly. Overall, HIF- $1 \alpha$ can provide an immediate reflection of tissue oxygenation at ADHF patients; however, we failed to demonstrate that HIF- $1 \alpha$ is a biomarker for predicting the risk of ADHF.

\section{Study limitations}

Our study had limitations. The sample scale and short follow-up time were disadvantages. Furthermore, to reduce patient discomfort, we did not perform arterial blood gas analysis. Moreover, we evaluated the degree of hypoxia in patients, so we did not detect HIF- $1 \alpha$ mRNA levels. Finally, the present study was a multicenter study. Even though all patients had received standard treatment according to the guidelines during the hospital stay, there were some minor differences in treatment between each study center, such as oxygen concentration and flow rate, as well as the dose of diuretics. These differences may have resulted in statistical bias.

\section{Conclusion}

The present study was the first to evaluate circulating levels of HIF- $1 \alpha$ in ADHF patients. HIF- $1 \alpha$, as an intracellular protein, was originally shown to exist in the circulation of ADHF patients. Serum HIF- $1 \alpha$ levels may reflect a serious state in patients with ADHF. Within the limitations of the study, serum HIF- $1 \alpha$ levels were not correlated with patient outcome. The HIF- $1 \alpha$ level may become a prognostic biomarker of heart failure; however; this potential role needs to be validated by means of further prospective studies in the future.

\section{Abbreviations}

ADHF: Acute decompensated heart failure; ATP: Adenosine triphosphate; BNP: B-type natriuretic peptide; CHF: Chronic heart failure; TAC: Transaortic constriction; VEGF: Vascular endothelial growth factor.

\section{Competing interests}

The authors declare that they have no competing interests.

\section{Authors' contributions}

GL had the original idea for the study, and drafted the manuscript. WHL carried out the enzyme-linked immunosorbent assay. XWW and JC recruited the subjects and performed the follow-up. ZHZ participated in its design and helped to draft the manuscript. RA performed the statistical analysis. ZZT participated in its design and supervised the study. All authors read and approved the final manuscript.

\section{Acknowledgments}

This study was supported by the Youth Fund of Wuhan General Hospital of Guangzhou Military Command. The authors would like to thank Dr Jian-hua Fan and colleagues from the Department of Ultrasonography of Wuhan General Hospital of Guangzhou Military Command for their invaluable help in realizing the study.

\section{Author details}

${ }^{1}$ Emergency Department, Wuhan General Hospital of Guangzhou Military Command, Wuhan 430074, China. ${ }^{2}$ Department of Thoracic Surgery, TongJi Hospital, TongJi Medical College, Huazhong University of Science and Technology, Wuhan, China. ${ }^{3}$ College of Foreign Language, Huazhong Agriculture University, Wuhan, China. ${ }^{4}$ Institute of Cardiology, Union Hospital, Tongji Medical College, Huazhong University of Science \& Technology, Wuhan, China.

Received: 11 March 2015 Accepted: 24 July 2015

Published online: 30 July 2015

\section{References}

1. Lehman JJ, Kelly DP. Gene regulatory mechanisms governing energy metabolism during cardiac hypertrophic growth. Heart Fail Rev. 2002;7:175-85.

2. Taegtmeyer H, Golfman L, Sharma S, van Arsdall M. Linking gene expression to function: metabolic flexibility in the normal and diseased heart. Ann NY Acad Sci. 2004;1015:202-13.

3. Levy D, Garrison RJ, Savage DD, DannelWB CWP. Prognostic implications of echocardiographically determined left ventricular mass in the Framingham heart study. N Engl J Med. 1990;322:1561-6.

4. Frohlich ED, Apstein C, Chobanian AV, Devereaux RB, Dustan HP, Dzau V, et al. The heart in hypertension. N Engl J Med. 1992;327:998-1008.

5. Semenza GL. HIF-1 mediates metabolic responses to intratumoral hypoxia and oncogenic mutations. J Clin Invest. 2013;123:3664.

6. Krishnan J, Suter M, Windak R, Krebs T, Felley A, Montessuit C, et al. Activation of a HIF-1a-PPARY axis underlies the integration of glycolytic and lipid anabolic pathways in pathologic cardiac hypertrophy. Cell Metab. 2009;9:512-24

7. Semenza GL. Hypoxia-inducible factor 1 and cardiovascular disease. Annu Rev Physiol. 2014;76:39-56.

8. Semenza GL. Regulation of metabolism by hypoxia-inducible factor 1. Cold Spring Harbor symposia on quantitative biology. Cold Spring Harb Perspect Biol. 2011;76:347-53.

9. Sarkar K, Cai Z, Gupta R, Parajuli N, Fox-Talbot K, Darshan MS, et al. Hypoxiainducible factor 1 transcriptional activity in endothelial cells is required for acute phase cardioprotection induced by ischemic preconditioning. Proc Natl Acad Sci. 2012;109:10504-9.

10. Cai Z, Luo W, Zhan H, Semenza GL. Hypoxia-inducible factor 1 is required for remote ischemic preconditioning of the heart. Proc Natl Acad Sci. 2013;110:17462-7.

11. Semenza GL. Hypoxia-inducible factors in physiology and medicine. Cell. 2012;148:399-408.

12. Sano M, Minamino $T$, Toko $H$, Miyauchi $H$, Orimo $M$, Qin $Y$, et al. p53induced inhibition of Hif-1 causes cardiac dysfunction during pressure overload. Nature. 2007:446:444-8.

13. Clerico A, Giannoni A, Vittorini S, Passino C. Thirty years of the heart as an endocrine organ: physiological role and clinical utility of cardiac natriuretic hormones. Am J Physiol Heart Circ Physiol. 2011;301:H12-20.

14. Goetze JP. Biosynthesis of cardiac natriuretic peptides. Results Probl Cell Differ. 2010;50:97-120.

15. Del Ry S, Cabiati M, Clerico A. Recent advances on natriuretic peptide system: new promising therapeutic targets for the treatment of heart failure. Pharmacol Res. 2013;76:190-8.

16. Fonarow GC, Peacock WF, Phillips CO, Givertz MM, Lopatin M. Admission B-type natriuretic peptide levels and in-hospital mortality in acute decompensated heart failure. J Am Coll Cardiol. 2007;49:1943-50.

17. Porapakkham P, Porapakkham P, Zimmet H, Billah B, Krum H. B-type natriuretic peptide-guided heart failure therapy a meta-analysis BNP-guided heart failure therapy. Arch Intern Med. 2010;170:507-14.

18. Berger R, Huelsman M, Strecker K, Bojic A, Moser P, Stanek B, et al. B-type natriuretic peptide predicts sudden death in patients with chronic heart failure. Circulation. 2002;105:2392-7.

19. Casals G, Ros J, Sionis A, Davidson MM, Jiménez MM. Hypoxia induces B-type natriuretic peptide release in cell lines derived from human cardiomyocytes. Am J Physiol Heart Circ Physiol. 2009;297:550-5.

20. Weidemann A, Klanke B, Wanger M, Volk T, Willam C, Michael S, et al. Hypoxia, via stabilization of the hypoxia-inducible factor HIF-1a, is a direct and sufficient stimulus for brain-type natriuretic peptide induction. Biochem J. 2008;409:233-42. 
21. Arjamaa O, Nikinmaa M. Hypoxia regulates the natriuretic peptide system. Int J Physiol Pathophysiol Pharmacol. 2011;3:191-201.

22. Chun YS, Hyun JY, Kwak YG, Kim IS, Kim CH, Choi E, et al. Hypoxic activation of the atrial natriuretic peptide gene promoter through direct and indirect actions of hypoxia-inducible factor-1. Biochem J. 2003;370:149-57.

23. Wilhide $M E$, Jones WK. Potential therapeutic gene for the treatment of ischemic disease: Ad2/hypoxia-inducible factor-1a (HIF-1)NP16 enhances B-type natriuretic peptide gene expressionvia a HIF-1-responsive element. Mol Pharmacol. 2006;69:1773-8.

24. McMurray JJ, Adamopoulos S, Anker SD, Auricchio A, Böhm M, Dickstein K, et al. ESC guidelines for the diagnosis and treatment of acute and chronic heart failure 2012: the task force for the diagnosis and treatment of acute and chronic heart failure 2012 of the European Society of Cardiology. Developed in collaboration with the Heart Failure Association (HFA) of the ESC. Eur J Heart Fail. 2012;33:1787-847.

25. Yancy CW, Jessup M, Bozkurt B, Butler J, Casey Jr DE, Drazner MH, et al. 2013 ACCF/AHA guideline for the management of heart failure: a report of the American College of Cardiology Foundation/American Heart Association Task Force on Practice Guidelines. J Am Coll Cardiol. 2013;62:e147-239.

26. Barnes SC, Collinson PO, Galasko G, Lahiri A, Senior R. Evaluation of Nterminal pro-B type natriuretic peptide analysis on the Elecsys 1010 and 2010 analysers. Ann Clin Biochem. 2004;41:459-63.

27. Mingles A, Jacobs L, Michelson E, Swedenborg J, Wooding W, van Diejien-Visser M. Reference population and marathon runners sera assessed by highly sensitive cardiac troponin $T$ and commercial cardiac troponin $T$ and I assays. Clin Chem. 2009;55:101-8.

28. Baumgartner H, Hung J, Bermejo J, Chambers JB, Evangelista A, Griffin BP, et al. Echocardiographic assessment of valve stenosis: EAE/ASE recommendations for clinical practice. J Am Soc Echocardiogr. 2009;22:1-23.

29. Robador PA, San José G, Rodríguez C, Guadall A, Moreno MU, Beaumont J, et al. HIF-1-mediated up-regulation of cardiotrophin-1 is involved in the survival response of cardiomyocytes to hypoxia. Cardiovasc Res. 2011;92:247-55.

30. Semenza GL. Oxygen sensing, homeostasis, and disease. N Engl J Med. 2011;365:537-47

31. Semenza GL. HIF-1 and mechanisms of hypoxia sensing. Curr Opin Cell Biol. 2001;13:167-71.

32. Huang LE, Gu J, Schau M, Bunn HF. Regulation of hypoxia-inducible factor $1 a$ is mediated by an O2-dependent degradation domain via the ubiquitin-proteasome pathway. Proc Natl Acad Sci. 1998;95:7987-92.

33. Chavez JC, Agani F, Pichiule P, LaManna JC. Expression of hypoxia-inducible factor-1 alpha in the brain of rats during chronic hypoxia. J Appl Physiol. 2000;89:1937-42.

34. Li G, Lu WH, Ai R, Yang JH, Chen F, Tang ZZ. The relationship between serum hypoxia-inducible factor 1alpha and coronary artery calcification in asymptomatic type 2 diabetic patients. Cardiovasc Diabetol. 2014;13:52.

35. Beyer C, Stearns NA, Giessl A, Distler JHW, Schett G, Pisetsky DS. The extracellular release of DNA and HMGB1 from Jurkat T cells during in vitro necrotic cell death. Innate immun. 2012;18:727-37.

36. Yu X, Deng L, Wang D, Li N, Chen X, Cheng X, et al. Mechanism of TNF-a autocrine effects in hypoxic cardiomyocytes: Initiated by hypoxia inducible factor 1a, presented by exosomes. J Mol Cell Cardiol. 2012;53:848-57.

37. Tang N, Wang L, Esko J, Giordano FJ, Huang Y, Gerber HP, et al. Loss of HIF-1a in endothelial cells disrupts a hypoxia-driven VEGF autocrine loop necessary for tumorigenesis. Cancer Cell. 2004;6:485-95.

38. Werno C, Menrad H, Weigert A, Dehne N, Goerdt S, Schledzewski K, et al. Knockout of HIF-1a in tumor-associated macrophages enhances M2 polarization and attenuates their pro-angiogenic responses. Carcinogenesis. 2010;31:1863-72.

39. Tekin D, Dursun AD, Xi L. Hypoxia inducible factor 1 (HIF-1) and cardioprotection. Acta Pharmacol Sin. 2010;31:1085-94

40. Silter M, Kögler H, Zieseniss A, Wilting J, Schäfer K, Toischer $K$, et al. Impaired $\mathrm{Ca} 2+-$ handling in $\mathrm{HIF}-1 \mathrm{a}+/$ - mice as a consequence of pressure overload. Pflugers Arch. 2010;459:569-77.

41. Zhang H, Qiana DZ, Tana YS, Lee KA, Gao P, Rene YR, et al. Digoxin and other cardiac glycosides inhibit HIF-1a synthesis and block tumor growth. Proc Natl Acad Sci. 2008;105:19579-86.

\section{Submit your next manuscript to BioMed Central and take full advantage of:}

- Convenient online submission

- Thorough peer review

- No space constraints or color figure charges

- Immediate publication on acceptance

- Inclusion in PubMed, CAS, Scopus and Google Scholar

- Research which is freely available for redistribution

Submit your manuscript at www.biomedcentral.com/submit 